удК 330.101

Е. М. Якимова

Байкальский государственный университет, 2. Иркутск, Российская Федеращия

\title{
К ВОПРОСУ О ФУНДАМЕНТАЛЬНОСТИ ПРЕДПРИНИМАТЕЛЬСКОЙ ДЕЯТЕЛЬНОСТИ КАК НАУЧНОЙ КАТЕГОРИИ
}

\begin{abstract}
АНнотАция. Ряд явлений представляют собой предельно общее понятие, выражающее наиболее существенные отношения, возникающие в действительности. Изучение категорий заключается в определении наиболее фундаментальных и широких классов сущностей. В статье с теоретических позиций рассмотрены особенности категории «предпринимательская деятельность». На основе изучения классификатора специальностей высшей научной квалификации, анализа научных разработок по различным научным направлениям сделан вывод о том, что предпринимательскую деятельность в той или иной мере изучают все науки. Вместе с тем, в зависимости от глубины изучения предпринимательской деятельности можно условно поделить две группы наук: изучающие непосредственно или опосредованно сущность самой предпринимательской деятельности как вида человеческой активности и изучающие предметы, на которые предпринимательская деятельность может быть направлена. Подобная междисциплинарность изучения предпринимательской деятельности позволяет всесторонне проанализировать различные стороны столько многогранного явления, но и требует от исследователей выявления сущности предпринимательской деятельности с учетом достижений других наук. Подобные научные заимствования позволяют выявить сущностные характеристики категории «предпринимательская деятельность», выявить тенденции развертывания явления по времени и пространстве.

ключЕВыЕ словА. Бизнес; категория; научное исследование; предпринимательская деятельность; экономическая теория.

ИНФОРМАЦИЯ О СТАТЬЕ. Дата поступления 17 января 2018 г.; дата принятия к печати 19 марта 2018 г.; дата онлайн-размещения 09 апреля 2018 г.
\end{abstract}

\author{
E. M. Yakimova \\ Baikal State University, \\ Irkutsk, Russian Federation
}

\section{ON ISSUE OF FUNDAMENTAL NATURE OF BUSINESS ACTIVITY AS A SCIENTIFIC CATEGORY}

\begin{abstract}
A number of phenomena represent an extremely general concept expressing the most essential relations arising in reality. Studying of categories consists of determining the most fundamental and wide classes of entities. The article considers the category of "business activity" in terms of theoretical positions. On the basis of studying the specialties nomenclature for highest of scientific qualification, analyzing scientific developments in various scientific directions a conclusion is drawn that business activity is studied to some extent by all sciences. At the same time, depending on the depth of studying the business activity it is possible to conditionally specify two groups of sciences: the ones studying directly or indirectly the essence of the business activity itself as a type of human activity and the ones studying the subjects to which the business activity can be directed. The similar interdisciplinarity of studying the business activity allows to analyze comprehensively various aspects of such a multifaceted phenomenon, but also demands from researchers the identification of the business activity essence taking into account the achievements of other sciences. Similar scientific borrowings allow to reveal the intrinsic characteristics of the «business activity» category, to identify the tendencies of this phenomenon's expansion in time and space.
\end{abstract}

\section{Baikal Research Journal}


KEYWORDS. Business; category; scientific research; business activity; economic theory. ARTICLE INFO. Received January 17, 2018; accepted March 19, 2018; available online April 09, 2018.

Отношения в социуме многогранны. Участие различных субъектов в развитии общества может рассматриваться другими участниками социума по-разному. Например, предприниматели в советское время считались преступниками, паразитами, наживающимися на нуждах населения. Подобная инвазивность предпринимательства выступала ключом к исследованию предпринимательства большинством представителей советской экономической школы. Данные основы находили отражение и в правовой мысли, налагали отпечаток на вектор научно-технического развития страны. Изменение конституционного строя России коренным образом трансформировало взгляд как на сам феномен предпринимательской деятельности, так и на основную задачу науки и техники, которой было провозглашено обеспечение потребностей общества. Таким образом, представляется логичным предположить, что изменение основ экономического строя России отразилось и на характере научных исследований, затрагивающих в том или ином виде предпринимательскую деятельность.

Научные представления о предпринимательской деятельности изначально были представлены в работах по экономической теории. Ирландский экономист Р. Кантильон (1680-1734) в работе «Очерк о природе торговли вообще» впервые использует термин «предприниматель» и «обосновывает особую роль предпринимателей в условиях европейского становления капитализма. Такой анализ позволил обнаружить в предпринимательстве экономические составляющие : действие частной собственности, необходимость поисков инноваций товаров и услуг в условиях рыночных отношений, личностную активность и креативность» [1, с. 58].

В настоящее время распространенным в исследованиях предпринимательской деятельности является изучение данного феномена представителями экономического и юридического блока наук. Так, по классификации ВАК (паспорт научных специальностей) в специальность 08.00.05 экономических наук входит подраздел «Экономика предпринимательства», в специальность 12.00.03 юридических наук входит подраздел «Предпринимательское право». Однако представляется, что предпринимательская деятельность в странах с элементами рыночной экономики обладает таким уровнем проникновения в различные сферы жизнедеятельности, что можно говорить о ее фундаментальности как явления. Представление о сущности предпринимательской деятельности высказываются представителями различных областей знаний, хотя, очевидно, что многие науки не рассматривают предпринимательскую деятельность как базис для своих исследований, хотя представители таких наук делают многое для становления и развития предпринимательской деятельности как деятельности, направленной на получение прибыли и удовлетворение интересов человека, общества и государства.

Следовательно, можно говорить о фундаментальности категории «предпринимательская деятельность», поскольку данный феномен является базисом для многих наук, изучение сущности предпринимательской деятельности создает основу для будущих исследований и прикладных разработок.

Универсальность предпринимательской деятельности как объекта изучения не означает, на наш взгляд, необходимость выделения отдельной науки, изучающей данное явление и его преломление в различных сферах жизнедеятельности, поскольку искусственно вычленять область знаний путем выделения части предмета экономических, юридических наук, а также заимствования некоторых

\section{Baikal Research Journal}


вопросов, связанных с осуществлением предпринимательской деятельности, из других отраслей знаний нецелесообразно и не отвечает целям научного познания. В данной связи можно вспомнить о споре «цивилистов» и «хозяйственников» по вопросу самостоятельности отрасли предпринимательского права : советские «цивилисты» были противниками не только выделения хозяйственного права (называемого в настоящее время предпринимательским правом), но и против принятия Хозяйственного кодекса СССР и союзных республик. Причем с переходом к рыночным принципам экономики спор решен не был, противостояние «цивилистов» и «хозяйственников» продолжается уже в рамках дискуссии о необходимости принятия Предпринимательского кодекса РФ.

Иными словами, комплексный подход к исследованию феномена предпринимательской деятельности, связанный с применением в процессе изучения данного явления достижений различных наук, представляется наиболее приемлемым, что однако порождает множество вопросов о том, какие науки изучают предпринимательскую деятельность. Представляется, что будет верным утверждение, что все науки в той или иной степени исследуют предпринимательскую деятельность, однако, ряд наук имеют одним из своих предметов само предпринимательство в различных его проявлениям (то есть направлены на получение достоверных знаний о самой деятельности), другие опосредованно связаны с предпринимательской деятельностью - они изучают предметы, на которые предпринимательская деятельность может быть направлена, по сути, это науки не изучают предпринимательскую деятельность, однако полученные представителями таких наук выводы могут быть использованы в процессе осуществлении производства, оказания услуг, выполнения работ и т.п., то есть связаны с реализацией бизнес-идей.

Доказывая справедливость обозначенного выше утверждения, рассмотрим, какой интерес к рассматриваемому явлению проявляют ученые двух вышеуказанных групп отраслей наук. Основой выделения отраслей наук служит Общероссийский классификатор специальностей высшей научной квалификации (принят и введен в действие приказом Федерального агентства по техническому регулированию и метрологии от 17 декабря 2013 г. № 2255-ст).

Первая группа наук подробно изучает различные явления, связанные с предпринимательской деятельностью, изучает характер возникших взаимосвязей и т.п. Условно, в ней можно выделить несколько подгрупп наук: 1) науки, непосредственно изучающие предпринимательскую деятельность; 2) науки, опосредованно изучающие предпринимательскую деятельность; 3) науки, в предмет изучения которых могут войти отдельные аспекты предпринимательской деятельности.

Среди наук первой подгруппы прежде всего можно выделить экономические науки, поскольку представители данных наук наиболее подробно изучили различные проявления построения, управления и функционирования бизнес-структур (экономика, менеджмент, маркетинг, бухгалтерский учет).

Экономические науки рассматривают предпринимательскую деятельность как с позиции макроэкономики, так и микроэкономики, что обусловлено тем, что именно изучение данной деятельности лежит в основе интереса экономических наук. Исследователи делают различные выводы о сущности предпринимательской деятельности. Несмотря на отсутствие единства мнений по вопросам выработки единой дефиниции предпринимательской деятельности, большинство авторов подтверждают тезис о том, что для современной экономики предпринимательство является основой, причем подчеркивается не только то, что бизнес-структуры участвуют в экономических процессах, но и то, что они выполняют «экономические функции по адаптации к внезапным изменениям на рынках» [2, с. 109].

\section{Baikal Research Journal}

электронный научный журнал Байкальского государственного университета 
Вторая подгруппа наук достаточно многочисленна, поскольку обозначенные общности знаний являются комплексными науками и в значительной степени изучают большинство явлений социального взаимодействия.

Так, исторические науки и археология уделяют внимание в том числе и причинам зарождения предпринимательской деятельности, факторам, влияющим на становление и развитие данного явления, правовым актам, устанавливающим основу государственного регулирования предпринимательской деятельности. Причинами зарождения предпринимательства называют наличие в обществе определенного уровня благосостояния и наличие рынков сбыта. Во многих странах зарождение предпринимательства связано «с возникновением возможности получения дохода новыми путями, от занятий различными ремеслами, например, ткачеством. Результаты деятельности работников, занятых ремеслами, обменивались по мере надобности на товары сельского хозяйства» [3, с. 99]. Стартом для развития предпринимательства является удовлетворение собственных нужд в производимом товаре и появление излишек.

Особый интерес среди нормативно-правовых актов российского государства, относящихся к предпринимательской деятельности, у исследователей вызывает Русская Правда, статья 54 которой описывала положение купца, ставшего, говоря современным языком, банкротом, Устав Главного магистрата 1721 года, в котором установлено, что городское население состоит в том числе из купцов двух гильдий, Таможенный устав 1755 года, разрешающий не купеческим сословиям торговать лишь изделиями и продукцией собственного производства, а остальными товарами - по «особой описи», Жалованная грамота городам 1785 года, принятая Екатериной II, предоставившая купечеству монополию на торговую деятельность, Конституция РСФСР 1918 г., закрепившая отмену частной собственности, национализацию земли, недр, вод, всего живого и мертвого инвентаря и т.д., Постановление Совета Министров СССР от 3 мая 1976 г «Об утверждении Положения о кустарно-ремесленных промыслах граждан», допускавшего мелкое частное хозяйство единоличных крестьян и кустарей, основанное на личном труде и исключающее эксплуатацию чужого труда, декрет Совета Народных комиссаров от 07 апреля 1921 г. «О потребительской кооперации», заложившего основы Новой экономической политики, Закон СССР от 02 апреля 1991 г. № 2079-1 «Об общих началах предпринимательства граждан в СССР», ставший одним из первых нормативно-правовых документов в процессе воссоздания отечественного законодательства о предпринимательской деятельности.

Юридические науки изучают границы предпринимательской деятельности с позиции установления правил поведения предпринимателей во взаимоотношениях с государством и обществом, а также реализации механизма правовой защиты прав предпринимателей. Тенденцией последнего времени является созданием специализированных государственных институтов содействия осуществлению прав предпринимателей в России, которые «несмотря на то, что являются государственными структурами способствуют становлению и развитию институтов гражданского общества» [4, с. 145].

Отметим, что особый интерес у правоведов представляет установление правил поведения субъектов предпринимательской деятельности с помощью правовых норм, а также сущность незаконного предпринимательства, анализ юридической ответственности за нарушение порядка осуществления рассматриваемой деятельности. Так, ведутся споры о корректности определения предпринимательской деятельности в Гражданском кодексе Российской Федерации, обсуждаются признаки данного явления, рассматриваются вопросы о соотношении предпринимательской и хозяйственной деятельности в рамках формулирования правовых конструкций.

\section{Baikal Research Journal}


В частности, Ю. Г. Лескова, А. А. Диденко поднимают вопрос о необходимости разграничения незаконной предпринимательской деятельности и незаконной профессиональной деятельности, поскольку «возрастание в российском бизнесе роли обязательного членства в саморегулируемых организациях, введенного взамен лицензирования отдельных видов предпринимательской или профессиональной деятельности, не могут не учитываться уголовным законом» [5, с. 96].

В отличие от экономических наук, в юриспруденции подход к пониманию предпринимательской деятельности значительно отличается в зависимости от того, представитель какой отрасли права изучает предпринимательскую деятельность. Так, публичные науки (например, конституционное, административное, уголовное право) большого внимание вопросам выработки дефиниции предпринимательской деятельности не уделяют, они рассматривают прежде всего проблемы обеспечения интересов общества и государства при осуществлении данной деятельности. Представителями частных наук (гражданское, трудовое право) ведутся споры не только о наличие у предпринимательской деятельности тех или иных признаков, но и о наличии отдельной отрасли права, которая бы обобщала знания о правовой регламентации осуществления предпринимательской деятельности (предпринимательском праве).

Для представителей юридической науки предпринимательская деятельность прежде всего объект правового регулирования, хотя на восприятие и учеными-юристами, и законодателями значительное влияние оказывает экономическая концепция, принятая государством за основу при построении взаимоотношений между государством и предпринимателями (признание приоритета социальную функции предпринимательства, или его экономической функции, или концепция необходимости уравновесить социальную и экономическую функцию предпринимательства).

Педагогические науки позволяют найти и применить методы обучения созданию и поддержанию эффективного функционирования бизнес-структур. Так, в диссертации на соискание ученого звания доктора педагогических наук на тему «Теоретические и методологические основы проектирования и реализации технологии интенсивного бизнес-обучения» Н. В. Жданько выделяет «жесткие» и «мягкие» навыки, причем предлагает при интенсивном бизнес-обучение ориентироваться на приобретение «мягких» навыков. Как отмечает исследователь, «мягкий» навык включает в себя «взаимообусловленные мотивационные, контекстные и алгоритмические характеристики деятельности, определение которых на этапах анализа потребностей в обучении и формирования программы обучения позволяет обеспечить результаты интенсивного обучения" $[6$, с. 6]. Таким образом, применение компетентностного подхода при осуществлении бизнес-обучения, в том числе проводимого в интенсивной форме, позволит приблизить обучение к задачам практической деятельности.

Философские науки, особенно такое направление как социальная философия, одним из предметов изучения имеют проблемы социальной ответственности бизнеса, представители данных наук издавна изучают вопросы о сущности денег, богатства. В философских науках предпринимательство может исследоваться в разделах «философия науки и техники» и «социальная философия». Причем, «наиболее результативным направлением анализа предпринимательства в постсоветской философии является философия науки и техники" [1, с. 58], поскольку комплексный подход позволяет структурировано рассмотреть сущность рассматриваемого явления.

Современным трендом философского учения выступает философия предпринимательства. В частности, Д. Сейдман из Принстонского университета считает,

\section{Baikal Research Journal}

электронный научный журнал Байкальского государственного университета 
что поскольку философов учат анализировать и искать новые подходы, они способны решать задачи в разных сферах современного общества. По его мнению, «философия может помочь нам сформулировать экзистенциальные проблемы, с которыми мир сталкивается сегодня, но только если мы вернем ее из дальнего угла и начнем активно применять в бизнесе» [7, с. 8].

Социологические науки позволяют выявить значение предпринимательства в процессе развития общества, проанализировать трансформацию общества в связи с изменением взаимодействия следующих субъектов: государство - предпринимательское сообщество, общество - предпринимательское сообщество. К примеру, в настоящее время активно исследуются вопросы, связанные с развитием социального предпринимательства, выявлением социальных факторов развития предпринимательства. А. Н. Асаул называет корпоративную ответственность предпринимательства новой философией бизнеса [8]. Интерес к таким явлением вызван, как представляется, повышением эффективности взаимодействия государства, общества и предпринимателей, представлением о том, что предпринимательская деятельность не только воздействует на рыночный механизм через систему производства и потребления, но и «позволяет сократить размер государственных расходов на социальную сферу, минимизировать искажения рыночного механизма и сохранить его эффективность» [9, с. 171].

Таким образом, изучение предпринимательской деятельности с позиции «непрофильных» наук позволяет применить метапредметный подход к изучению феномена предпринимательства.

Примером третьей подгруппы наук могут быть биологические науки, поскольку в предмет их изучения подпадают в том числе и последствия осуществления предпринимательской деятельности для биосферы (например, исследователи экологических проблем выявляют различные аспекты влияния предпринимательской деятельности на состояние окружающей среды).

В частности, медицинские науки, в том числе, исследуют влияние работы на определенных предприятиях на здоровье сотрудников. Например, выводы представителей этих наук стали основой для формирования термина «профзаболевание», установление необходимости выплаты повышенной заработной платы работникам, например, осуществляющим трудовую деятельность в условиях Крайнего Севера.

Для психологических наук важным является выполнение рефлексивной функции. Применительно к предпринимательской деятельности выводы представителей данных наук позволяют выйти в рефлексивную позицию, осознать познавательные средства поведения различных сторон отношений, возникающих при осуществлении предпринимательской деятельности. Исследования в области психологии часто направлены на выработку методов успешного осуществления предпринимательской деятельности, поскольку «эффективность предпринимательской деятельности определяется степенью личной успешности предпринимателя и предполагает наличие психологических факторов, обуславливающих эту успешность» [10, с. 51], а именно наличие таких черт, как здравый смысл, знание своего дела, уверенность в собственных силах, наличие гибкого подхода, способности корректировать деятельность при изменении внешних условий, высокий общий уровень развития, способность доводить дело до конца.

В рамках политологии исследуются в том числе политические институты, процессы и технологии с позиций возможности применения данных знаний для лоббирования интересов бизнес-структур во взаимодействии с органами власти, осуществления ребрендинга коммерческих компаний, осуществляющих продвижение на политическом рынке. Существует понимание того, что эффективное

\section{Baikal Research Journal}

электронный научный журнал Байкальского государственного университета 
использовать существующих легальных каналов защиты интересов бизнеса, возможно только при их глубоком изучении и применении знаний на практике. Если рассматривать лоббизм в рамках одного государства, то наблюдается тенденция усиления лоббирования интересов бизнеса через участие в экспертной подготовке решений, что позволяет государству сэкономить бюджетные средства путем перекладывания расходов на экспертную подготовку решений на частный бизнес. Кроме того, лоббизм бизнес-структур становится неотьемлемой частью отстаивания интересов в международных организациях. $\mathcal{K}$ примеру, «деятельность лоббистов на уровне Европейского Союза является «международным лоббизмом», так как основное воздействие направлено на межправительственные и наднациональные институты власти ЕС. Такой уровень лоббизма используется для того, чтобы оказать влияние на национальные государства через структуры власти ЕС. Европейские ассоциации бизнеса выступают в качестве международных неправительственных организаций, которые могут использовать межгосударственные объединения для защиты своих интересов в третьих странах» [11, с. 13].

Культурология также исследует некоторые аспекты предпринимательской деятельности. В частности, в последнее время активно развивается изучение культуры предпринимательства через призму построения цивилизованного бизнеса [12]. Подобная постановка вопроса отражает проблему поиска баланса между социальной и экономической функцией государства, которую давно активно обсуждают представители экономических и юридических наук.

Вторая группа наук не изучает предпринимательскую деятельность, но выводы представителей данных наук могут быть использованы в процессе ее осуществлении, потребность предпринимателей в решении какой-то бизнес-задачи может стать причиной изучения какого-либо предмета, что может привести к научным открытиям.

Например, достижения физико-математических наук могут быть использованы при создании новых способов построения бизнес-моделей, получения прибыли из новых инструментов (примером является, в частности, появление криптовалют, которые в настоящее время являются источником прибыли и в некоторых странах средством оплаты за услуги). Проникновение наук о земле в сферу изучения предпринимательской деятельности осуществляется аналогичным образом, к примеру, технологии и техника геологоразведочных работ интересны не только как теоретические конструкции, но и как реальный способ получения ресурсов, которые используются в предпринимательской деятельности.

Технические науки совершенствуют процесс осуществления предпринимательской деятельности, в частности, изучая мехатронику и робототехнические системы.

Сельскохозяйственные науки изучают, в частности, технологии повышения прибыли сельхозпроизводителей.

Филологические науки изучают, в частности, средства доставки информации о товарах и услугах до потребителей и контрагентов.

Искусствоведение непосредственно не изучает предпринимательскую деятельность, однако предметы искусства могут являться объектом различных товарно-денежных операций. Кроме того, учебный план подготовки искусствоведов во многих вузах (например, Санкт-Петербургском университете профсоюзов ${ }^{1}$ ) предполагает соединение в образовательном процессе нескольких составляющих. Во-первых, собственно искусствоведческая подготовка как продолжение традиций классического университетского образования. Во-вторых, так называемое,

${ }^{1}$ Кафедра искусствоведения / СПбГУП, 2018. URL: http://www.gup.ru/uni/structure/faculties/ art_fac/structure/ kaf_art/.

\section{Baikal Research Journal}

электронный научный журнал Байкальского государственного университета 
прикладное искусствоведение, блок учебных дисциплин, посвященных практике художественного рынка. Этот компонент искусствоведческого образования имеет целью формирование у студентов системных знаний в сфере отечественного и международного художественного рынка и предпринимательства. Студенты изучают закономерности функционирования художественного рынка и его структуру, место и роль художественного бизнеса в системе экономических отношений, роль современных информационных технологий в его функционировании, процессы ценообразования на художественном рынке, специфику предпринимательской деятельности в различных сферах художественной культуры.

Анализ преломления различных достижений в понимании феномена предпринимательской деятельности позволяет сделать определенные выводы.

Все науки можно условно поделить на две большие группы: изучающие непосредственно или опосредованно сущность самой предпринимательской деятельности как вида человеческой активности и изучающие предметы, на которые предпринимательская деятельность может быть направлена. Подобная междисциплинарность предпринимательской деятельности позволяет всесторонне проанализировать различные стороны столько многогранного явления, но и требует от исследователей пониятие сущности предпринимательской деятельности, учета достижений других наук при ее изучении. Подобные научные заимствования позволяют выявить сущностные характеристики явления, позволить установить движущую силу трансформации того или иного явления, выявить тенденции развертывания явления по времени и пространстве.

Многогранность предпринимательской деятельности обуславливает различия в целях, способах, инструментах изучения предпринимательской деятельности не только в рамках различных отраслей науки, но и в рамках различных групп специальностей внутри одной отрасли науки. Например, менеджмент изучает управление, в том числе, внутри бизнес-структуры, бухгалтерский учет исследует принципы и способы отражения стоимостных результатов предпринимательской деятельности, экономика предпринимательства обобщает особенности системы производства, распределения, обмена и потребления товаров и услуг в рамках прежде всего рыночной экономики с участием предпринимателей. Таким образом, экономические науки изучают феномен предпринимательства, однако делают это по-разному, что обусловлено спецификой предмета и методов изучения различных явлений данными науками.

\section{Список использованной литературы}

1. Павлович А. А. Направления анализа предпринимательства в постсоветской философии / А. А. Павлович // Вестник Пермского национального исследовательского политехнического университета. Культура, история, философия, право. - 2016. - № 3. - С. 56-64.

2. Руденко В. Н. Методика анализа практики предпринимательства в контексте теории микроэкономики / В. Н. Руденко // Известия Иркутской государственной экономической академии (Байкальский государственный университет экономики и права). - 2010. № $3(71)$. - C. $107-109$.

3. Пеньков П. Е. История возникновения и развития предпринимательства на Руси / П. Е. Пеньков, В. В. Кабанов // Вестник Евразийской академии административных наук. - 2014. - № 2 (27). - С. 99-106.

4. Микова Е. Б. Финансовый уполномоченный и медиация как новые институты защиты конституционных прав граждан Российской Федерации / Е. Б. Микова // Известия Иркутской государственной экономической академии (Байкальский государственный университет экономики и права). - 2012. - № 4 (84). - С. 145-148.

5. Лескова Ю. Г. Незаконное предпринимательство: изменение признаков состава уголовного преступления в свете реформирования гражданского законодательства РФ /

\section{Baikal Research Journal}

электронный научный журнал Байкальского государственного университета 
Ю. Г. Лескова, А. А. Диденко // Криминологический журнал Байкальского государственного университета экономики и права. - 2016. - Т. 10, № 1. - С. 96-104. - DOI : 10.17150/1996-7756.2016.10(1).96-104.

6. Ж данько Н. В. Теоретические и методологические основы проектирования и реализации технологии интенсивного бизнес-обучения : дис. ... д-ра пед. наук : 25.00.25 / Н. В. Ж данько. - М., 2012. - 581 с.

7. Сейдман Д. Отношение определяет результат / Д. Сейдман. - М. : Манн, Иванов и Фербер, 2017. - 400 с.

8. Асаул А. Н. Новая философия предпринимательства - корпоративная социальная ответственность /А. Н. Асаул // Управленческие науки. - 2014. - № 4. - С. 30-37.

9. Кадол Н. Ф. Социальное предпринимательство в рыночной и переходной экономике : дис. ... канд. экон. наук : 08.00.01 / Н. Ф. Кадол. - М., 2009. - 184 с.

10. Камнева Е. В. Психология успешного предпринимательства / Е. В. Камнева, Н. В. Анненкова // Научный вестник МГИИТ. - 2012. — № 6 (20). - С. 51-58.

11. Чернышева В. А. Лоббирование интересов бизнеса в политических органах и институтах ЕС : автореф. дис. ... канд. полит. наук : 23.00.04 / В. А. Чернышева. - М., 2013. $-23 \mathrm{c}$.

12. Демьянчук А. С. Сущность предпринимательской культуры / А. С. Демьянчук // Бизнес в законе. - 2008. - № 2. - С. 338-341.

\section{References}

1. Pavlovich A. A. Trends analysis of the phenomenon «business» in post-soviet philosophy. Bulletin of PNRPU. Culture. History. Philosophy. Law, 2016, no. 3, pp. 56-64. (In Russian).

2. Rudenko V. N. Procedure of practice analysis in the context of the theory of microeconomics. Izvestiya Irkutskoi gosudarstvennoi ekonomicheskoi akademii = Izvestiya of Irkutsk State Economics Academy, 2010, no. 3 (71), pp. 107-109. (In Russian).

3. Penkov P. E., Kabanov V. V. History and development of entrepreneurship in Russia. Vestnik Evraziiskoi akademii administrativnykh nauk = Herald of the Eurasian Academy of Administrative Sciences, 2014, no. 2 (27), pp. 99-106. (In Russian).

4. Mikova E. B. Financial authorized representative and mediation as new institutions to protect the constitutional rights of citizens of the Russian Federation. Izvestiya Irkutskoi gosudarstvennoi ekonomicheskoi akademii = Izvestiya of Irkutsk State Economics Academy, 2012, no. 4 (84), pp. 145-148. (In Russian).

5. Leskova Yu.G., Didenko A.A. Illegal entrepreneurship: changing the attributes of criminal offense corpus delicti in the light of Russian civil legislation's reform. Kriminologicheskii zhurnal Baikal'skogo gosudarstvennogo universiteta ekonomiki i prava = Criminology Journal of Baikal National University of Economics and Law, 2016, vol. 10, no. 1, pp. 96-104. DOI: 10.17150/1996-7756.2016.10(1).96-104. (In Russian).

6. Zhdanko N. V. Teoreticheskie $i$ metodologicheskie osnovy proektirovaniya i realizatsii tekhnologii intensivnogo biznes-obucheniya. Dr. Diss. [Theoretical and methodological fundamentals of designing and implementing the technologies of intensive business learning. Dr. Diss.]. Moscow, 2012. 581 p.

7. Seidman Dov How: Why How We Do Anything Means Everything. New Jersey, John Wiley \& Sons, 2011. 384 p. (Russ. ed.: Seidman D. Otnoshenie opredelyaet rezul'tat. Moscow, Mann, Ivanov i Ferber Publ., 2017. 400 p.).

8. Asaul A. N. Corporate social responsibility as the new philosophy of business Upravlencheskie nauki = Management sciences, 2014, no. 4, pp. 30-37. (In Russian).

9. Kadol N. F. Sotsial'noe predprinimatel'stvo $v$ rynochnoi i perekhodnoi ekonomike. Kand. Diss. [Social business in market and transitional economy. Cand. Diss.]. Moscow, 2009. 184 p.

10. Kamneva E. V., Annenkova N. V. Psychology of successful entrepreneurship. Nauchnyi Vestnik MGIIT = Scientific Bulletin MSIIT, 2012, no. 6 (20), pp. 51-58. (In Russian).

11. Chernysheva V. A. Lobbirovanie interesov biznesa $v$ politicheskikh organakh $i$ institutakh ES. Avtoref. Kand. Diss. [Lobbying business interests in political bodies and institutes of European Community. Cand. Diss. Thesis]. Moscow, 2013. 23 p.

12. Demyanchuk A. S. Essence of business culture. Biznes $v$ zakone $=$ Business in Law, 2008, no. 2, pp. 338-341. (In Russian).

\section{Baikal Research Journal}




\section{Информация об авторе}

Якилова Екатерина Михайловна - кандидат юридических наук, доцент, кафедра правового обеспечения национальной безопасности, Байкальский государственный университет, 664003, г. Иркутск, ул. Ленина, 11, e-mail: yakimova_katerin@mail.ru.

\section{Author}

Ekaterina M. Yakimova - PhD in Law, Associate Professor, Chair of Legal Provision of National Security, Baikal State University, 11 Lenin St., 664003, Irkutsk, e-mail: yakimova_ katerin@mail.ru.

\section{Для цитирования}

Якимова Е. М. К вопросу о фундаментальности предпринимательской деятельности как научной категории / Е. М. Якимова // Baikal Research Journal. - 2018. - T. 9, № 1. - DOI : 10.17150/2411-6262.2018.9(1).1.

\section{For Citation}

Yakimova E. M. On Issue of Fundamental Nature of Business Activity as a Scientific Category. Baikal Research Journal, 2018, vol. 9, no. 1. DOI: 10.17150/2411-6262.2018.9(1).1. (In Russian).

\section{Baikal Research Journal}

